\title{
Challenges of Local Government, Environmental Justice, Sustainable Development: The Case of Qellem Wollega Zone, Oromia Regional State, Ethiopia
}

\author{
Jemal Hussein Abdulle \\ College of Social Sciences, Oda Bultum University, Chiro, Ethiopia \\ Email address: \\ Jemalhussein7@gmail.com \\ To cite this article: \\ Jemal Hussein Abdulle. Challenges of Local Government, Environmental Justice, Sustainable Development: The Case of Qellem Wollega \\ Zone, Oromia Regional State, Ethiopia. American Journal of Environmental Protection. Special Issue: Enhancing Natural Resource \\ Conservation for Sustainable Development. Vol. 9, No. 3, 2020, pp. 67-76. doi: 10.11648/j.ajep.20200903.15
}

Received: August 19, 2019; Accepted: May 27, 2020; Published: June 28, 2020

\begin{abstract}
Currently, environment related problem is becoming a burning issue for every individuals and group of people living in the globe irrespective of our background as we have only one world that can't be replaced by another one. We don't have a reserve world therefore the only chance that we have is conserving it. Therefore, different scholars today have taken up to come across possible remedies as the issue is multidisciplinary in its nature. This problem is also visible in Ethiopian society at local level. One way of tackling environmental problem is giving attention to the impacts of environmental injustice on sustainable development. Therefore, this research tries to assess challenges of local government in storing up environmental justice to realize sustainable development. The main finding of this research is that the local government has less contribution in storing up environmental justice to realize sustainable development in the given areas. There is no enough awareness creation from government side regarding resettlement policy in a way that the re-settlers are not friendly treating their environment. Re-settlers are doing injustice on old settlers, future generations, living and non-living things, and on themselves since they have over-exploited natural resources in concerned areas. I used both primary and secondary datum to carry out this research. I suggest that concerned government bodies, civil societies or non-governments organizations should play their part to alleviate the problems.
\end{abstract}

Keywords: Environment, Environmental Injustice, Environmental Justice, Government, Natural Resources, Over-exploitation, Resettlement, Sustainable Development

\section{Introduction}

The very concept of environmental justice is one of the prominent issues in the history of environmental ethics. According to David Schlosberg, the most often and popular meaning of environmental justice is fair distribution of environmental goods and bads to all humans [1]. Finger and Zorzi also state, "[e] nvironmental justice is the recognition of disparities among people in costs and benefits distribution, meaning that the concept is in fact a call for equality" [2]. According to Victor Munnik, the notion of environmental justice will be realized when the relations between peoples with themselves and with their environments are fair and equal without imposing unfair or excessive burdens on others and their environments, now and in the future [3]. According to Filomina C. Steady [4], the "environmental Justice is the fair treatment for people of all races, cultures and incomes, regarding the development of environmental laws, regulations and policies." Steady argues that the conceptual underpinning of environmental justice is fair distribution of environmental goods and burdens to all peoples irrespective of race, color, culture, income, religion etc in accordance with the environmental laws, regulations and policies [3].

The notion of environmental injustice, which is a direct opposite to environmental justice, is the serious human problem that resulted from the unequal distribution of environmental benefits and burdens across different communities because of different factors like race, class, and gender. The idea of environmental injustice begun in the 
United States of America in 1980s in response to the distribution of environmental hazards like toxic waste and incinerators, adjacent to communities inhabited by people of color and poor people [1-6]. This issue has attracted the attention of many environmental activists and scholars at different times in history; they have tried to discuss the notion of environmental injustice in numerous studies [7, 8, 9]. According to Carmin and Agyeman [7], communities of color (black Americans, Indian Americans and other minorities) and lower income classes in the United States have been at disproportionate risk from commercial toxic wastes or environmental "bads", such as the site of hazardous waste landfills, polluting industries, hazardous materials, health hazard, work place hazard and the emission of toxic chemicals into the air and water. Similarly, environmental "goods", such as a safe work place, clean water and air, easy access to natural surroundings or parks and open spaces have been unequally distributed among the general population. In other words, environmental injustice implies the practice of targeting the communities of color in the United States, as a repository of toxic waste sites that end-up in environmental pollution and discrimination.

According to Brundtland Commission's definition, the notion of sustainable development means "development that meets the needs of the present without compromising the ability of future generations to meet their own needs" [10]. Alan Holland also argues that the idea of sustainability reflects development of a kind that does not prejudice future development and acceptable environmental modification is needed [10]. Unlike the traditional view of development, sustainable development concentrates on perpetuating the interest of the present people without harming the interest of the future generations though we cannot be assured of what would be their interest exactly. At least we can guess some points regarding the interest of the future generations based on the interest of the present generations.

The very concept of environmental injustice has devastating impacts on sustainable development in one way or the other. In this study, I will concentrate on the overexploitation of natural resources caused by Oromo of Hararge migrated to Qellem Wollege Zone, Hawa-galaan, Odaa Megersa and waltaha gemechu villages. They are exploited natural resources for immediate purpose that can have devastating impacts on societies at large. In other words, these people are over- exploited the forest to sustain their basic needs without considering the interests of future generations. The overall objective of this study is to investigate challenges of local government in storing-up environmental justice as a tool to 'realize' sustainable development in case of Oda Megersa and Waltaha Gemechu villages, Hawa-galan district, Qellem Wollega Zone, Oromia National Regional State. I argue that achieving genuine human development in Hawaa-galaan district needs meaningful environmental justice framework. It means, both environmental justice and sustainable development share many things in common.

\section{Research Design and Methodology}

Research design is the framework that is created to seek answers to the research questions which results in revealing particular understanding on the matters being researched. The study uses descriptive case research design to assess challenges of local government in storing-up environmental justice as a tool to 'realize' sustainable development in case of Oda Megersa and Waltaha Gemechu villages, Hawa-galan District, Qellem Wollega Zone, Oromia National Regional State. This design preferred mainly to describe major constraints those inhibiting to realize environmental justice to bring sustainable development. Based on the time required to accomplish the research, the study will be uses a cross sectional research design because this enable researcher to collect data from many people at one particular point in time. Moreover, mixed research approach (quantitative and qualitative research approach) was employed to fulfill incompleteness of one another. Hence, quantitative and qualitative data are incorporated to resolve the research questions. Quantitative data was collected from respondents using close ended questions while qualitative data obtained from the key informants and focus group discussants to get more insight to address the research questions.

\subsection{Sources of Data}

In this study, both secondary and primary data are incorporated through data collection techniques. To support the qualitative statement, the study uses quantitative method to triangulate. To collect secondary data, published and unpublished materials are considered, which are available in the form of books, journals, articles, proclamations, policy briefs, federal and regional constitutions, laws, regulations, performance reports, and pertinent academic concerns. In addition, primary data were obtained from local people, representatives and officials of district, particularly, from purposively selected kebeles (Oda Megersa and Waltaha Gemechu).

\subsection{Methods of Data Collection}

Different methods of data collection were employed, those are deemed to be appropriate and enable to acquire the necessary information, to address the research questions and possibly lead to credible research findings. The methods are discussed below.

\subsubsection{Interview}

From interview, semi structured interview are employed to obtain data from key informants, who are assumed to have particular information on relevant issues that can provide wealth of information for the researcher. Hence, Development agents, kebele chief, kebele manager, kebele religious leaders and head of agriculture office were interviewed face to face..

\subsubsection{Focus Group Discussions}

The focus group discussions were used for experts those 
involved in agricultural activities of different departments. 12 experts (focus discussants in two for manageable reason) will be selected since they can provide wealth data in due study.

\subsubsection{Questionnaires}

Questionnaire is a method of gathering information from respondents about attitudes, knowledge, feelings and their beliefs. Questionnaires were administered to the local people of the selected kebeles (head of household). These questionnaires include open ended and close ended questions.

\subsubsection{Reviewing Documents and Literatures}

Secondary datum, published and unpublished materials were considered, like books, journals, articles, proclamations, policy briefs, federal and regional constitutions, laws, regulations, performance reports, and pertinent academics.

\subsection{Sample Technique}

Non-probability and probability sampling techniques were employed to select case study area and samples from the population. The researcher purposively selected two kebeles (Oda Megersa and Waltaha Gemechu) from QellemWollega, Oromia National Regional State to investigate challenges of assessing local government in storing up environmental justice to realize sustainable development. The reason for selecting these two kebeles is based on the magnitude of environmental injustice visibility. Furthermore, researcher was purposely selected the key informants and focus group discussants that are expected to provide valuable information. From probability sampling, the study uses Stratified Random Sampling and then sample from the sub lists. Then after, systematic random sampling used to identify respondent.

Sample size determination

As statistical data of the district, the two selected kebeles have 541 households, which are the unit analysis of the study. Based on the total households of the kebeles, sample size will be determined using Slovenes' formula, considering a level of acceptable margin of error at $5 \%$.

$$
\mathrm{n}=\frac{\mathrm{N}}{1+\mathrm{Ne}^{2}}=230 \text { households }
$$

Where

$\mathrm{N}=$ target population

$\mathrm{n}=$ desired sample size

$\mathrm{e}=$ marginal error

Therefore, the sample size of each kebele is determined by stratified sampling formula as follows:

$\mathrm{ni}=(\mathrm{n} / \mathrm{N}) \mathrm{Ni}$

$\mathrm{Ni}=$ population of size in stratum

$\mathrm{n}=$ total sample size

$\mathrm{N}=$ total number of elements in population of all strata

$\mathrm{ni}=$ the sample size in stratum $\mathrm{i}$

kebele oda megersa $=(230 / 541) 261=111$ households

kebele Waltaha gemechu= $(230 / 541) \quad 280=119$ households

Table one is presented in the table below.
Table 1. Sample size population drawn from each kebele.

\begin{tabular}{llll}
\hline S/N & Kebele selected & $\begin{array}{l}\text { Target } \\
\text { population }\end{array}$ & $\begin{array}{l}\text { Share of one kebele } \\
\text { from unit of analysis }\end{array}$ \\
\hline 1 & Oda Megersa & 261 & 111 \\
2 & WaltahaGemechu & 280 & 119 \\
Total & & 541 & 230 \\
\hline
\end{tabular}

Source: Own Survey.

\subsection{Data Analysis}

Quantitative data entered to SPSS version 20 for the statistical analysis which were presented using percentage, tables or diagrams as they are simple to work with and easy to comprehend while qualitative data are analyzed by description and triangulation methods.

\subsection{Ethical Considerations}

All the information collected from participants is confidential and will be maintained as such. Permission to collect the datum need letter from institution or University. Knowledge of the nature and purpose of the study as well as expected roles and activities were explained. The participants were informed about the aims and the purpose of the study as well as no any potential risk that may arise emanating from the study. Participants were informed where appropriate, about all aspects of the research, especially its aims and implications in order to influence their willingness to participate. Clear and fair arrangements are first considered with the participants and respondents of the study before involving or engaging them in such process. All guarantees of privacy, confidentiality, anonymity were honored and participants are not coerced or humiliated.

\section{Results and Discussion}

\subsection{Farming Experience of the Respondents}

Table 2. Respondents' view on farming experience.

\begin{tabular}{llll}
\hline farmex & Freq. & Percent & Cum. \\
\hline $0-6$ & 7 & 3.04 & 3.04 \\
$7-10$ & 51 & 22.17 & 25.22 \\
$11-15$ & 114 & 49.57 & 74.78 \\
above 15 & 58 & 25.22 & 100.00 \\
Total & 230 & 100.00 & \\
\hline
\end{tabular}

The above table shows that majority 114 (49.57\%) of the farmers have 11-15 years of farming experience. 58 (25.22) respondents are indigenous people who are living since long period of time. $51(22.17 \%)$ respondents are settlers who are living 7-10 years. $7(3.04 \%)$ respondents are settlers whom farm experience is from $0-6$ years. Therefore, the finding of this research shows that majority of target population is migrants.

\subsection{Attitudes of People About Migration}

The respondents have expressed their attitudes about migration as follows: 
Table 3. Respondents'attitude towards migration.

\begin{tabular}{llll}
\hline Migration & Freq. & Percent & Cum. \\
\hline very good & 60 & 26.09 & 26.09 \\
good & 146 & 63.48 & 89.57 \\
neutral & 22 & 9.57 & 99.13 \\
bad & 2 & 0.87 & 100.00 \\
Total & 230 & 100.00 & \\
\hline
\end{tabular}

It shows that majority $146(63.48 \%)$ of the respondents have replied that they have good perception about migration. $60(26.06 \%)$ of respondents have very good attitudes about migration. $22(9.57 \%)$ respondents are neutral about migration. Therefore, the findings of this study reveals that target population have clearly understood the notion of migration and they have good attitudes regarding migration.

To support the above idea, another study shows the positive aspects of resettlement. The finding of Nakai [11] on resettlement shows that it has a potential to strengthen local capacities. Furthermore, resettlement can improve increasing access to various livelihood assets and resources. It can bring significant improvement in physical capital such as shelter, more land and road access, and communication infrastructure.

\subsection{Impacts of Migration on Environment}

Table 4. Respondents' attitude toward impacts of migration on environment.

\begin{tabular}{llll}
\hline impmig & Freq. & Percent & Cum. \\
\hline yes & 159 & 69.13 & 69.13 \\
no & 51 & 22.17 & 91.30 \\
I don't know & 20 & 8.70 & 100.00 \\
Total & 230 & 100.00 & \\
\hline
\end{tabular}

Regarding impacts of migration on the environment the data collected from the respondents indicate that the majority $159(69.13 \%)$ of the respondents argued that it has high impacts on migration. $51(22.17 \%)$ of the respondent replied that it has no impacts on environments whereas the remaining $20(8.70 \%)$ of the respondents are neutral about the impacts of migration on the environment. Therefore, the finding of this study revealed that migration has high impacts on climate change. To support this idea the data collected from focus group discussants revealed that migration has high impacts on the environments in the ways that migrants have over-exploited much natural resources to sustain their life

To support the above result, Frank Laczko and Christine Aghazarm put impacts of migration on environment as such:

The literature on climate change and migration is generally very pessimistic about mobility arising from climate change. This creates a starting point bias in thinking about policy responses, eschewing the development of policies that seek to harness migration as a strategy to promote adaptation to climate change [12].

There has been an overwhelming tendency to focus on the negative consequences of migration for the environment, with fewer studies exploring how migration can be a coping or adaptation strategy or how migration can relieve pressure on environmentally degraded areas. In addition, they further explore "the negative portrayal of migration can foster policies that seek to reduce and control its incidence and do little to address the needs of those who migrate, when migration may be the only option for those affected by climate hazards"[12].

\subsection{Governments' Consultation for Both Indigenous and Settlers before Migration}

Table 5. Attitude of respondents towards governments' consultation for indigenous and settlers before migration.

\begin{tabular}{llll}
\hline govcon & Freq. & Percent & Cum. \\
\hline very good & 25 & 10.87 & 10.87 \\
good & 146 & 63.48 & 74.35 \\
neutral & 54 & 23.48 & 97.83 \\
bad & 5 & 2.17 & 100.00 \\
Total & 230 & 100.00 & \\
\hline
\end{tabular}

The majority $146(63.48 \%)$ of respondents have replied that government's consultation about migration before migration has taken was good. 54 (23.48) respondents have replied with neutral about government's consultation. 25 $(10.87 \%)$ of respondents have replied that there was very good consultation from the government about the concerned issue. Finally, only $5(2.17 \%)$ of respondents have replied that it's bad. Therefore, the finding of this study suggests that government has consulted the communities before migration has taken.

To support this finding, Shumete Gizaw says extensive awareness has carried out regarding how to utilize natural resources. To put in his words, "subsequent training has been provided to the re-settlers on how to utilize the existing resources in a sustainable and environmentally friendly manner. A number of nursery sites have been established. Community woodlots establishment was also on progress" [13]. In contrast to Shumete's observation regarding awareness of resource utilization given for re-settlers by government, the key informants claim that there were huge losses of forest and other natural resources compared with the pre-resettlement time. The re-settlers were provided with no education and advice about environmental degradation. It was observed that collective facilities were put in place by the government for use by re-settlers but the majority was found with limited capacity. The shared agreement among all the respondents was that their current livelihood situation is by far better than the former one and they do not dream to return to their origin.

\subsection{Society's Culture of Conserving Sacred Trees}

Table 6. Respondents' views toward culture of conserving sacred trees

\begin{tabular}{llll}
\hline consac & Freq. & Percent & Cum. \\
\hline very good & 2 & 0.870 .87 & \\
good & 52 & 22.61 & 23.48 \\
neutral & 86 & 37.39 & 60.87 \\
bad & 88 & 38.26 & 99.13 \\
very bad & 2 & 0.87 & 100.00 \\
Total & 230 & 100.00 & \\
\hline
\end{tabular}


The majority $88(38.26 \%)$ of respondents revealed that there is bad culture of conserving sacred trees. 86 (37.39\%) of respondents have replied that they don't even have an ideas about sacred trees. $52(22.61 \%)$ said that there is good culture of conserving sacred trees. $2(0.87 \%)$ replied that there is good culture of it. The remaining $2(0.87 \%)$ of them replied it's very bad culture of conserving sacred trees. As a result, the finding of this study indicated that concerned peoples are not aware about sacred trees and there is no conservation for the concerned trees.

Furthermore, Samantha M. Jones [14] reveals that societies' protection of sacred trees appears uncertain however, as acculturation has led some caretakers to abandon traditional stewardship. According to Jones, only few societies like the people of Mangio and Vuchama, two North Pare highland villages, are still maintaining sacred forests. But most of societies in Tanzania are reducing the culture of preserving sacred trees.

\subsection{Society's Culture of Conserving or Replacing Forests After Clearing for Purpose}

Table 7. Respondents' view towards replacing forests after cutting it.

\begin{tabular}{llll}
\hline Confor & Freq. & Percent & Cum. \\
\hline Yes & 39 & 16.96 & 16.96 \\
No & 165 & 71.74 & 88.70 \\
I don't know & 26 & 11.30 & 100.00 \\
Total & 230 & 100.00 & \\
\hline
\end{tabular}

Most 165 (71.74\%) of people responded that there is no culture of replacing forests after cutting or clearing for different purposes. $39(16.96 \%)$ of respondents were positively argued for the culture of replacing forests after clearing it. $26(11.30 \%)$ of the respondents have no clue about it. Therefore, the finding of this study shows that respondents have no culture of conserving forests after deforestation has taken place for various purposes. In addition, the focus group discussants revealed that peoples even don't have enough awareness about conservation of natural resources for the reason that there are enough natural resources in the concerned areas. But for now the areas are turning to be very hot or radical climate change is taking place because of deforestation.

\subsection{Temperature vis-à-vis Migration}

Table 8. Respondents'view regarding the relation between temperature and migration.

\begin{tabular}{llll}
\hline Climcha & Freq. & Percent & Cum. \\
\hline Yes & 176 & 76.52 & 76.52 \\
No & 45 & 19.57 & 96.09 \\
I don't know & 9 & 3.91 & 100.00 \\
Total & 230 & 100.00 & \\
\hline
\end{tabular}

Majority $176(76.52 \%)$ of the respondents have replied that temperature has increased after migration has taken place whereas $45(19.57 \%)$ respondents haven't experienced temperature change after migration. The rest of the respondents were neutral about temperature after migration.

\subsection{Climate change and Farming}

Table 9. Respondents' attitude on climate change and farming.

\begin{tabular}{llll}
\hline Climcha & Freq. & Percent & Cum. \\
\hline Yes & 161 & 70.00 & 70.00 \\
no & 54 & 23.48 & 93.48 \\
I don't know & 15 & 6.52 & 100.00 \\
Total & 230 & 100.00 & \\
\hline
\end{tabular}

Majority $161(70 \%)$ of respondents have replied that they have experienced climate change since they started farming. $54(23.48 \%)$ of respondents said that there is no climate change since they started farming whereas the remaining 15 $(6.52 \%)$ of the respondents are neutral about it. In addition, the focus group discussants were revealed that there is high rate of climate change since they started farming. So, the finding of this research shows that migrants have played a pivotal role in climate change. In addition, the datum I have collected from focus group discussants revealed that since majority of the residents are migrants and they have exploited natural resources for different purposes, they became the source of climate change. My expectation is that migration has impacts on climate change. To support the above view, another studies revealed as follows;

As far as the increase in the local temperature is concerned, fairly more than half $(51.5 \%)$ of the respondents described that it has moderately increased and $40.8 \%$ reported that the temperature in their locality was highly increased over time due to forest degradation and only $7.9 \%$ replied that the temperature has increased in a lesser amount in their area [14].

My finding and the above quotation have somehow correlation even though they have slight difference. According to Girma, there is climate change that resulted from expansion of agricultural land due to population boom in a given areas. Mine is also the same even though the major cause of temperature increment is migration.

\subsection{Resettlement and Environment}

\subsubsection{Impacts of Migration on the Environments from Migrant Points of View}

Table 10. Migrants' view regarding impacts of migration on the environment.

\begin{tabular}{llll}
\hline Impmigset & Freq. & Percent & Cum. \\
\hline Yes & 94 & 55.29 & 55.29 \\
no & 67 & 39.41 & 94.71 \\
I don't know & 9 & 5.29 & 100.00 \\
Total & 170 & 100.00 & \\
\hline
\end{tabular}

$94(55.29 \%)$ of settlers responded that there is impacts of migration on the environments after migration whereas 67 $(39.41 \%)$ of them replied that there is no impacts of migration on the environments after migration. 9 (5.29\%) of them are neutral about it. In addition, focus group discussants were revealed that after we came here for farming we have exploited natural resources that can end up in conquering the environments through different means. The questionnaire looks like repetition but this is not without reason. The 
reason is to compare the perception of both settlers and indigenous peoples on the same issues. My expectation is that these settlers can harm environments to sustain their life. According to Jason Bremner and Lori M. Hunter put their view as such;

Migrants who move for economic and livelihood reasons may affect the environment where they settle. Research conducted at the Carolina Population Center has analyzed the long-term environmental impacts of colonization of the Ecuadorian Amazon by settlers from other parts of the country. 16 As oil companies established new roads in the Amazon for oil exploration, drilling, and production, migrants arrived from the highlands of Ecuador to claim newly available land. Surveys collected in 1990 and 1999 were linked with satellite imagery and have revealed a pattern of initial deforestation as households established plots along roads, followed by a longer-term trend of continued land clearing as farms were further subdivided into smaller and smaller plots [15].

\subsubsection{Impacts of Migration on the Environments from Native people's Points of View}

Table 11. Native peoples'view on impacts of migration on the environment.

\begin{tabular}{llll}
\hline impmigind & Freq. & Percent & Cum. \\
\hline Yes & 54 & 90.00 & 90.00 \\
no & 5 & 8.33 & 98.33 \\
I don't know & 1 & 1.67 & 100.00 \\
Total & 60 & 100.00 & \\
\hline
\end{tabular}

Majority $54(90 \%)$ of respondents said that migration has impacts on the environments whereas $5(8.33 \%)$ of them argued there is no impacts of migration on the environments. Only $1(1.67 \%)$ of them is neutral about it. In addition, focus group discussants (indigenous people to the area) said that migration has tremendous impacts on environment. For instance, before they migrated here for farming the area was covered by jungle but they have deforested for farming, housing, over-grazing, charcoal and other factors that can open the way for expansion of desertification.

To support my finding, Kyle Powys Whyte says that settlers have impacts on the environment in many ways. To put in his own words;

Settler colonial theory, on my interpretation, offers a structure of oppression based on one society's interference with and erasure of another society. Given that the process described earlier is deeply ecological, settler colonial theory is always about environmental injustice. That is, settler societies seek to establish their own collective continuance at the expense of the collective continuance of another society. Settler societies impose preventable harms on indigenous peoples to facilitate the former's process of homeland inscription. The homeland inscription process replaces indigenous social institutions, ecologies and experiences with settler social institutions, ecologies and experiences. The cornerstone of this conception of EJ is its phenomenology of how people experience the world. A form of environmental change is unjust when one society robs another society of the institutional and ecological conditions required for members of another society to experience the world in ways that motivate their engagement in the operation of systems of responsibilities [16].

The above quotation conveys that settlers have impacts on indigenous social institutions, ecologies and experiences. But here my intension is not to create a difference between indigenous and settlers in areas of my studies but just to show that settlers became source of environmental degradation. Therefore, let the concerned bodies, with settlers and indigenous peoples, struggle to alleviate hazardous environmental problems happing in the areas of my study.

\subsubsection{Over-exploitation of Natural Resources like Animals, Forests, and Medicinal Trees}

Table 12. Respondents' view toward over-exploitation of natural resources.

\begin{tabular}{llll}
\hline Overex & Freq. & Percent & Cum. \\
\hline Yes & 179 & 77.83 & 77.83 \\
no & 41 & 17.83 & 95.65 \\
I don't know & 10 & 4.35 & 100.00 \\
Total & 230 & 100.00 & \\
\hline
\end{tabular}

Majority $179(77.83 \%)$ of respondents revealed that there is over-exploitation of natural resources is in the given areas. Whereas $41(17.83 \%)$ of respondents replied that there is no experience of over-exploitation in respective area. 10 $(4.35 \%)$ of respondents were neutral about the given issue. The finding of this study reveals that over-exploitation is happing in the areas of my selection because of different factors like over-population, deforestation, mining, overgrazing, agriculture, and so on.

There are other studies that reveal the same finding with mine. Tadesa Girma reveals the same finding with mine. He says that over-exploitation is significant in many countries of the world. And it arises from natural resource based economic development and its consequents [17]. Furthermore, he claims that causes of depletion of natural resources are includes: over-population, inefficiency in resource utilization, overconsumption, poverty and other socioeconomic problems, deforestation, mining, commercial logging, construction of dam reservoirs, urbanization and industrialization, forest fires, overgrazing, and many others [17]. Furthermore, he claims; "poverty contributes to environmental degradation in most of the agriculture based developing countries as for example farmers living in poverty may let the immediate need to produce food outweigh the long term benefits of convening land" [17].

\subsubsection{Resettlement and Its Disadvantage}

Table 13. Respondents'view on resettlement and its disadvantage.

\begin{tabular}{llll}
\hline Lackres & Freq. & Percent & Cum. \\
\hline yes & 173 & 75.22 & 75.22 \\
no & 37 & 16.09 & 91.30 \\
I don't know & 20 & 8.70 & 100.00 \\
Total & 230 & 100.00 & \\
\hline
\end{tabular}

Majority $173(75.22 \%)$ of respondents revealed that they 
have things that they lacked because of resettlement. Whereas $37(16.09 \%)$ of respondents replied that there is nothing that they lacked because of resettlement. $20(8.70 \%)$ of respondents were neutral about the given issue. The finding of this study shows what people are lacked because of resettlement is natural resources as I have mentioned in somewhere else. A lot of natural resources like animals, forests, medicinal trees, sacred plants and many others are destructed of resettlement.

\subsubsection{Resettlement and Its Advantage}

Table 14. Respondents 'view on resettlement and its advantage.

\begin{tabular}{llll}
\hline Gainedres & Freq. & Percent & Cum. \\
\hline Yes & 188 & 81.74 & 81.74 \\
No & 37 & 16.09 & 97.83 \\
I don't know & 5 & 2.17 & 100.00 \\
Total & 230 & 100.00 & \\
\hline
\end{tabular}

Majority $188(81.74 \%)$ of respondents revealed that they have things that they have gained because of resettlement. Whereas $37(16.09 \%)$ of respondents replied that there is nothing that they have gained because of resettlement. 5 $(2.17 \%)$ of respondents were neutral about the given issue. Therefore, the finding of this study shows that re-settlers have gained economic improvements after they shifted to the concerned areas. Furthermore, the focus group discussants have revealed that there is significant livelihood improvement for concerned peoples. In other words, they have shown significant improvement of livelihoods particularly economic empowerment. But a huge impact on environment is visible. Furthermore, the areas are exposed for climate change, increasing of temperature, conflicts on natural resources, over-exploitation of natural resources and the like. To support this view, Food and Agriculture Organization (FAO) reported as follows;

Migration from, to and between rural areas is an important component of both international and internal migration. The reallocation of labour from less productive to more productive sectors of the economy is an integral component of economic development [18].

Food and agriculture organization (FAO) reveals that rural migration has integral contribution for economic development but environmental degradation.

\subsubsection{Conflicts on Natural Resources'Sharing}

Table 15. Respondents' view on conflicts on natural resources sharing.

\begin{tabular}{llll}
\hline Connat & Freq. & Percent & Cum. \\
\hline Yes & 146 & 63.48 & 63.48 \\
No & 64 & 27.83 & 91.30 \\
I don't know & 20 & 8.70 & 100.00 \\
Total & 230 & 100.00 & \\
\hline
\end{tabular}

Majority $146(63.48 \%)$ of respondents revealed that conflicts on natural resources is visible. Whereas 64 $(27.83 \%)$ of respondents replied that there is no conflicts on natural resource sharing. $20(8.70 \%)$ of respondents were neutral about the given issue. The finding shows that there are conflicts on natural resource sharing. In addition, focus group discussants reveal that there is conflict on natural resources. They also said that of course conflict is widely exacerbated after Oromo of Hararge have migrated to the concerned areas. In other words, majority of respondents have revealed that conflicts over natural resources is widely experienced since Hararge people have migrated to concerned areas.

But here conflict is not the racial one rather its conflict of interest among the same group, families, village, and so on. There is no racial difference for concerned societies in the first place. In other words, both indigenous and settlers are from the same racial group. Furthermore, another study shows the same result. According to Toadrian P. Wood, there are different types of natural resource conflicts can be identified in terms of the actors involved [19]. For him, one type of conflict is intra-group conflicts between different socio-economic groups within an ethnic group [19].

\subsubsection{The Number of People with Available Lands}

Table 16. Respondents 'view on available lands vis-à-vis number of people.

\begin{tabular}{llll}
\hline Peopland & Freq. & Percent & Cum. \\
\hline very good & 56 & 24.35 & 24.35 \\
good & 99 & 43.04 & 67.39 \\
neutral & 56 & 24.35 & 91.74 \\
bad & 19 & 8.26 & 100.00 \\
Total & 230 & 100.00 & \\
\hline
\end{tabular}

Majority $146(63.48 \%)$ of respondents revealed that number of people with available land is good. There is no scarcity of resources. Whereas $56(24.35 \%)$ of respondents replied that number of people with available land is very good. $56(24.35 \%)$ of respondents were neutral about the given issue. $19(8.26 \%)$ of them said that there is bad relation between people available land. The finding of this study reveals that there is enough land access with available population.

\subsection{Assessment of Communal Forest Management Initiative}

Table 17. Respondents' view on assessment of communal forest management.

\begin{tabular}{llll}
\hline comforest & Freq. & Percent & Cum. \\
\hline very good & 18 & 7.83 & 7.83 \\
good & 103 & 44.78 & 52.61 \\
neutra & 69 & 30.00 & 82.61 \\
bad & 40 & 17.39 & 100.00 \\
Total & 230 & 100.00 & \\
\hline
\end{tabular}

Majority $103(44.78 \%)$ of respondents revealed that communal forest management initiative is good. This indicate that majority of the people have awareness about trends of communal forest initiative. 69 (30\%) of the respondents are neutral about the given issue. This manifests that a lot of people have not awareness about it. 40 (17.39\%) of the respondents are said that trends of communal forest initiative is bad. Whereas $18(7.83 \%)$ of them said that there is very good experience of the given issue. So, the finding of this study shows that people have awareness about communal 
forest initiative (participatory forest management). In line with the above view, Ellen Winberg says;

Participatory Forest Management is quite new to Ethiopia it was first implemented 13 years ago. As such, it is difficult to know the exact expanse of PFM forests and project areas in Ethiopia. Data on the current area coverage is lacking. Only by including the respondents from this study, the coverage in 2010 will be more than 211076 hectares of forest. Only half of the organizations that are included in this study managed to report area surface of their PFM forests. There are also a number of additional actors in PFM whose coverage is unknown to this study [20].

There are some common features across the different PFM implementers when it comes to their strategies for PFM introduction and implementation. Firstly, the PFM idea is generally introduced by an external actor, such as an NGO or a local authority. Overall, the components of PFM are concentrated around: forest development management that can include plantation and reforestation or rehabilitation of degraded lands; forest protection and utilization; monitoring of the forest and evaluation of the management following this. Emphases on these different topics vary between the implementers and are often complemented by activities aimed to improve livelihoods [20].

\subsubsection{Perceptions of Living Society for the Future Generations}

The focus group discussants have said that we, the people who are living now, have a moral responsibility to protect and save limited natural resources for the coming generation. But the current generations are not properly using the current natural resources as the future generations are also going to use the same natural resources that we are using now. Now we are conquering the nature as we concentrate widely on fostering our interest. In other words, we are unjustly treating future generation with regard to natural resource sharing. I argue that the notion of development shouldn't be interpreted only in terms of fulfilling material resources but also it has to consider the environment we live in now and saving it for the coming generation.

\subsubsection{Resettlement and Conservation of Natural Resources}

Table 18. Respondents' view on resettlement and conservation of natural resources.

\begin{tabular}{llll}
\hline rescons & Freq. & Percent & Cum. \\
\hline yes & 157 & 68.26 & 68.26 \\
no & 55 & 23.91 & 92.17 \\
I don't know & 18 & 7.83 & 100.00 \\
Total & 230 & 100.00 & \\
\hline
\end{tabular}

Majority 157 (68.26\%) of respondents revealed that there is a connection between resettlement program and conservation of natural resources. $55(23.91 \%)$ of the respondents are said there is no connection between the two issues. Whereas $18(7.83 \%)$ of the respondents are neutral about concerned issue. Resettlement can negatively impact natural resources for the reason that farmers exploit natural resources to sustain their life through different mechanisms. There is less conservation of natural resources where there is resettlement program undertaken.

\subsubsection{Resettlement and Economic Development}

Table 19. Respondents' view on resettlement and economic development.

\begin{tabular}{llll}
\hline Resesus & Freq. & Percent & Cum. \\
\hline very good & 11 & 4.78 & 4.78 \\
good & 94 & 40.87 & 45.65 \\
neutral & 72 & 31.30 & 76.96 \\
bad & 53 & 23.04 & 100.00 \\
Total & 230 & 100.00 & \\
\hline
\end{tabular}

Majority 94 (40.87\%) of respondents have revealed that there is good relationship between resettlement and economic development. $72(31.30 \%)$ of the respondents are neutral about the given issue. $53(23.04 \%)$ of the respondents are said that there is bad relation between the two. Whereas 11 $(4.78 \%)$ of them said that there is very good relation between the two. The finding of this study reveals that there is good relation between resettlement and economic development. As focus group discussants reveal that there is good relation between resettlement and economic empowerment. But the problem is the connection between resettlement and sustainable development for there is negative correlation. It means that resettlement can hinder to realize the meaning and scope of sustainable development. Sustainable development (SD) goes beyond the scope of traditional notion of development which focuses on material well being or economic empowerment. But SD gives attention for environmental preservation, economic empowerment, and even the interest of the future generation. Since resettlements negatively impact the environment and the interest of the future generation, it will contradict with the scope of sustainable development. Therefore, there is negative relationship between resettlement and sustainable development as the information I got from focus group.

\subsubsection{Positive Benefits of Resettlement}

Key informants reveal that resettlement has played lion share in improving over-all livelihood of the re-settlers in the concerned areas of study. As I mentioned somewhere, resettlers have shown significant improvement especially with regard to economic empowerment. In line with this view, FAO 2019 reveals that "rural migration will continue to be an essential element of processes of economic and social development. Developing clear and coherent policies, both for migration and for rural development more broadly, is essential for a successful process of development that can benefit migrants, their areas of origin and their areas of destination" [18]. Furthermore, Shumete Gizew says that "the resettlement plan aims to ensure and assist people to develop their social and economic potential in order to improve their incomes and living standards that are not worse off than they would have been without resettlement [13].

Furthermore, Shumete shows that resettlement of people from eastern to western oromia is a voluntary one as it targets food security. It focuses on food necessity of the people at 
risk has been at the core of resettlement agenda. Migrated people are chronically food insecure families from environmentally degraded, moisture deficit, and high population areas to potentially productive areas of Oromia region in Ethiopia [13]. But the key informants claim that there were huge losses of forest and other natural resources compared with the pre-resettlement time.

Personally, I suggest that where resettlement is inevitable, detailed research, imaginative planning, concerned institutional building, participation of re-settlers and receiving communities, and proper preparation should be made. In line with this view, both government and nongovernment organizations should play their part to create awareness regarding resource utilization and minimize environmental degradation.

\section{Conclusion and Recommendation}

\subsection{Conclusion}

The finding of this study shows that there is less government consultation for re-settlers before and after migration has taken place. The re-settlers have exploited the environment for immediate purpose and unfriendly manner. They have achieved the over-all aspects of human life especially that interest related with material well-being. But they fail to consider the interest of the future generations as they concentrate on human centeredness approach of environment. In other words, re-settlers have fulfilled traditional aspect of development which focuses on economic growth. The modern notion of development like concept of sustainable development is likely not considered in the selected areas of this study. Furthermore, the current generations are not considering the interest of the future generations. Based on this assumption, the current generations are committing environmental injustice on the coming generation. So this study reveals that local, regional, and national governments have contributed lessto negotiate the interest of different groups like old-settlers, new resettlers, and future generations.

Furthermore, Oromo of Hararge, migrated to the concerned area, focuses on sustaining their immediate question of human life that is basic need or economic empowerment. Am not saying that government re-settlement program is bad, the issue is that the newly re-settled people need to live friendly with the environment without pushing the right of indigenous (old-settlers) people to live in the safe heaven place of their environment. The old settlers are facing temperature change that is resulted from over-exploitation of natural resourcesby new migrants to the areas. This is one form of environmental injustice on indigenous people. Government re-settlement policy is failed to work on let new and old settlers environmentally friend. There is no awareness creation or training from government regarding how to implement the notion of sustainable development which considers the interest of current generations, future generations, animals, plants, all living and non-living things at the same time.

\subsection{Recommendation}

Local, regional, and national government should work together to make concerned societies to live friendly with the environment. In other words, all government levels should play their role to come-across the problem of environmental degradation in concerned areas. In addition, NGO's and other stake holders should turn their eyes to these pressing human problems. Above all, Oromo of Hararge, who re-settled in the new environment, are responsible to consider the interest and right of the indigenous people, future generations, animals, and care for natural resources.

\section{References}

[1] Schlosberg, David.(2007) Defining Environmental Justice: Theories, Movements, and Sen, Nature. New York and Oxford: Oxford University Press.

[2] Finger, Marina de Oliveira and Zorzi, Filepe Bortoncello. (2013) "Environmental Justice." V1, pp. 222-243.

[3] Munnik, Victor. (2007) "Solidarity for Environmental Justice in Southern Africa." A Report for groundwork. Available from http://www.groundwork.org.za/Publications/SolidarityforEJin SA.pdf

[4] Steady, Filomina C. (2009) "Introduction", in Fillomina, Steady (ed.) Environmental Justice in the New Millennium: Global Perspectives on Race, Ethnicity, and Human Rights. New York: Palgrave Macmillan, pp. 1-16.

[5] Shrader- Frechette, Kristin (2002) Environmental Justice: Creating Equality, Reclaiming Democracy. Oxford: Oxford University Press.

[6] Pellow, David N. (2007). Resisting Global Toxics: Transnational Movements for Environmental Justice. Cambridge, Massachusetts and London: The MIT Press.

[7] Agyeman, Julian et al (eds.) Just Sustainabilities: Development in an Unequal World. UK and USA: EARTHSCAN Publications Ltd, pp. 38-63.

[8] Adeola, Francis O. (2001) "Environmental Injustice and Human Rights Abuse: The States, MNCs, and Repression of Minority Groups in the World System." Human Ecology Review, No. 1, V. 8, pp. 39-59.

[9] Bullard, Robert. D (1990) Dumping in Dixie: Race, Class, and Environmental Quality. 3rd ed. Central Avenue, Boulder, and Colorado: Westview Press.

[10] UlHaq, Mahbub. (1995) Reflections on human development: How the focus of development economics shifted from national income accounting to people-centred policies, told by one of the chief architects of the new paradigm. New York and Oxford: Oxford University Press.

[11] Vilaynanh Phoneppraseuth. (2012) From Resettlement to Sustainable Livelihood Development: The Potential of Resettlement and Livelihood Restoration Arrangement to Achieve livelihood Sustainability. Massey University, Palmerstone North, New Zealand.. 
[12] Frank Laczko and Christine Aghazarm. (2009) Migration, Environment and Climate Change: Assessing the Evidence, International Organization for Migration (IOM), Geneva, Switzerland.

[13] Shumete Gizaw. (2013) Resettlement Revisited: The PostResettlement Assessment in Biftu Jalala Resettlement Site. EJBE Vol. 3 No. 1/2013.

[14] Jones, Samantha. (2013) Sacred Forests and the Social Dimensions of Conservation in the North Pare Mountains of Tanzania: MS Thesis, University of Dodoma, Dodoma press, Tanzania.

[15] Jason Bremner and Lori M. Hunter. (2104) Migration and the Environment: Population Bulletin 69, no. 1.

[16] Kyle Whyte. (2017) Indigenous Experience, Environmental Justice and Settler Colonialism. Michigan State University.
[17] Tadesse, Girma. (2018) Aspects of Deforestation and Efforts of Forest Conservation in Selected Kebeles of GobaWereda, Bale Zone, Oromia Regional State.

[18] FAO. (2018) The State of Food and Agriculture 2018: Migration, Agriculture and Rural Development. Rome. Licence: CC BY-NC-SA 3.0 IGO.

[19] Wood, Adrian. (1993) Natural Resource Conflicts in SouthWest Ethiopia: State, Communities, and the Role of the National Conservation Strategy in the Search for Sustainable Development: University of Huddersfield, UK.

[20] Ellen Winberg (2011) Participatory Forest Management in Ethiopia, Practices and Experiences: Food and Agriculture Organization of the United Nations Sub-regional Office For Eastern Africa, Addis Ababa, Ethiopia. 